\title{
EFFECT OF ANTENATAL CARE ON MATERNAL AND NEONATAL OUTCOMES IN WOMEN'S HEALTH HOSPITAL
}

\author{
*Nadia Hussien Ahmed, **Eman Abd El-Aziz Mohamed \\ * Assistant Professor of Obstetrics \& gynecological nursing, Faculty of Nursing, Assiut University, \\ Egypt \\ ** Lecturer of pediatric nursing, Faculty of Nursing, South Valley University, Egypt
}

\begin{abstract}
Introduction: Good antenatal care (ANC) reduces maternal and neonatal mortality and improves health outcomes, particularly in low-income countries. World Health Organization recommendation of initiation of antenatal care within the first four months of pregnancy and at least four antenatal care visits during the course of an uncomplicated pregnancy. Inadequate care during this time breaks a critical link in the continuum of care and affects both women and her neonate. Objectives: The aim of the study was to identify effects of antenatal care on maternal and neonatal outcomes in Women Health Hospital Subjects \& Method: Three hundred parous women and their neonates conducted a comparative study. They were divided into two groups' according to parity the first group (primipara $=150$ ), and the second group (high parity=150) and divided every group into two groups the first was poor antenatal care and other was adequate antenatal care during the period from February 2017 to August 2017 using a stratified sampling. Results: Most of the primipara women had poor antenatal care $(88 \%)$ but high parity $(67.3 \%)$. There was the highly significant relationship between two groups. More than half were had poor antenatal care $(60.3 \%)$ but less than half were adequate antenatal care. The most common complication in primipara group was eclampsia $(36.4 \%)$ while in high parity group was anemia $(14.3 \%)$ in poor antenatal care. The most common complication in labor was premature rupture of membrane $(19.0 \% \& 14.3 \%)$ respectively, in poor antenatal care of two groups. In primipara group, the proportion of low birth weight was $16.0 \%$ in poor antenatal care, while stillbirth was $(11.0 \%)$ inadequate antenatal care also neonatal weight in $\mathrm{Kg}$ related to poor antenatal care and adequate antenatal care were $(2.636 \pm 0.659$ \& $3.050 \pm 0.503)$ respectively. In high parity group, the proportion of Special Care Baby Units admission was $12.2 \%$ in poor antenatal care, while Special Care Baby Unit admission was $11.9 \%$ inadequate antenatal care also neonatal weight related to poor antenatal care and adequate antenatal care were $(2.973 \pm .709 \& 3.081 \pm 0.643)$ respectively. Conclusion: Good quality antenatal care promote the health of the mother and decreases the percentage of iron deficiency anemia, gestational hypertension and before term labor and promote maternal outcomes, including a reduced risk of under birth weight, preterm neonates and Special Care Baby Unit admission. Recommendations: the women should have access to good quality antenatal care. Both the woman and the neonatal are at a greater risk during pregnancy and labor. This risk can be reduced with good antenatal care and delivery by trained personnel. And awareness of the adverse impact of high parity on obstetric Keywords: Antenatal care, high Parity, neonatal outcome, primipara, Pregnancy outcome
\end{abstract}

\section{Introduction:}

Good quality antenatal care improves maternal health; decreases the chances of suffering from anemia, pregnancy- induced hypertension, and preterm labor and promote positive pregnancy outcomes, including a reduced risk of 
low birth weight and preterm babies. Antenatal care increases the use of a skilled birth attendant during delivery and postnatal care because the visit can be an opportunity to educate women about the merits of skilled birth attendance. Antenatal care visits provide an excellent opportunity to deliver education regarding the danger signs and symptoms during pregnancy, delivery and the postpartum period and to focus on birth spacing and family planning Joshi, Torvaldsen, Hodgson \& Hayden (2014); Abbas, Ahmed, Alam Eldin and Ahmed (2017).

The World Health Organization recommends at least four antenatal care visits. While globally estimates that only about fifty percent of all pregnant receive this recommended antenatal care. In Egypt, only sixty-six percent had regular antenatal care UNICEF (2015).

Good quality antenatal care promote the health of the mother and decreases the percentage of iron deficiency anemia, gestational hypertension and before term labor Yakoob, Menezes, Soomro, Haws, Darmstadt, Bhutta (2009) and improve pregnancy outcomes, involve a decreased risk of under birth weight $<2,500 \mathrm{Kg}$ and preterm neonate Tuladhar \& Dhakal (2011)

Antenatal care is essential for maternal and neonatal health. The main reasons have been explained the importance of ANC for pregnant: promotion of health during pregnancy by counseling and educational programs, screening, identification and referral of women with high-risk factors; and health assessment throughout pregnancy Ahmed, Khoja \&Tirmizi (2012).

The most recent maternal and child health data (2009) reported for Vermont indicate $83 \%$ of pregnant women received early (first trimester) prenatal care. $9.2 \%$ of births were preterm $(<37$ weeks), $6.7 \%$ were low birth weight
$(<2500 \mathrm{~g})$, and Vermont's infant mortality rate (death prior to one year of age) was 6.1 deaths per 1000 . While these rates are better than the national averages, many risk factors can be addressed to further improve maternal and infant health outcomes. Early prenatal care, achieving a healthy weight, moderate exercise, a healthy diet, reducing stress, and avoiding exposure to smoking, alcohol, illegal drugs and some medications all are positive steps women can take to reduce risks. These improvements are often supported by providing women with education and support, effective care coordination, and linkage with health and community resources Racine (2011); Abbas et al., (2017).

Good care during pregnancy is important for the health of the mother and the development of the unborn baby. Pregnancy is a crucial time to promote healthy behaviors and parenting skills. Good ANC links the woman and her family with the formal health system, increases the chance of using a skilled attendant at birth and contributes to good health through the life cycle. Inadequate care during this time breaks a critical link in the continuum of care and affects both women and babies. Anavhe. (2015).

A huge number of infants whose birth weight below normal and requiring Neonatal Intensive Care Unit admission result from pregnancy-related complications. Eleven percent of newborns were born prematurely as by WHO estimates Chakraborty \& Anderson (2011). Different conditions with different prevalence cause complication of pregnancy. The hypertensive disease is seen in five to eight percent of pregnancies Mugo, Dibley \& Agho (2015). PROM is linked to significant maternal and fetal morbidity and mortality Liu, Feng, Wu 
EFFECT OF ANTENATAL CARE ON MATERNAL AND etc...

(2010). Maternal complications include intra-amniotic infection, which occurs in $13 \%-60 \%$ of women with PROM, placental abruption, and postpartum endometritis El-Messidi, \& Cameron (2010). Pre-term birth, infection, hypertensive disease, and asphyxia are cited as the most common contributors to maternal and fetal mortality in developing countries Vogel, Lee, Souza (2014). Common causes for Oligohydramnios were idiopathic (56\%) and PIH (24\%). Most common reason to perform cesarean was fetal distress Bhat \& Kulkarni (2015). These complications differ from primipara to multipara. The Tuladhar \& Dhakal (2011) study aimed to assess the occurrence of complications among two parity groups (primipara and multipara) in relation to antenatal care.

Different conditions with different prevalence cause complication of pregnancy. The hypertensive disease is seen in five to eight percent of pregnancies Mugo et al., (2015). PROM is linked to significant maternal and fetal morbidity and mortality Liu et al., (2010). Maternal complications include intra-amniotic infection, which occurs in $13 \%-60 \%$ of women with PROM, placental abruption, and postpartum endometritis El-Messidi \& Cameron (2010). Pre-term birth, infection, hypertensive disease, and asphyxia are cited as the most common contributors to maternal and fetal mortality in developing countries Vogel, Lee, Souza (2014). Common causes for Oligohydramnios were idiopathic (56\%) and PIH (24\%). Most common reason to perform cesarean was fetal distress Bhat S \& Kulkarni V (2015). WHO has estimated that prevalence of anemia in developed and developing countries in pregnant women are $14 \%$ and $51 \%$ respectively and in India. The consequences of anemia are serious and include economic losses, maternal mortality and adverse birth outcomes

Singh, Devi, Gandhi, Vimal (2018).

Several factors lead to the decreased incidence of grand multipara in western countries such as: improving the economic condition, more utilization of resources and the increased usage of contraceptive methods. Ahmed, et al (2012) when the problem of grand multiparity is joined to the low socioeconomic condition, it leads to the higher rate risks to the mother and her baby which further lead to lower feeding, clothing and education resources. However, this problem is rare in developed countries with the rate from one to four percent UNICEF. (2015); Erin, Christopher, Angeline, Alma, Job, Ivo \& Suparat (2014); Tuladhar \& Dhakal (2012) El-zanty \&Way A. (2011).

Many of these mothers have increased risk because of the poor economic condition which leads to limited access to antenatal services, lack of nutrition, repeated pregnancies, and lactation which lead to the diminished store of calcium and iron. El-zanty F \&Way A.(2011); Erin et al., (2014) and Titaley, Hunter, Heywood \& Dibley (2010). These reported complications that occur in these groups of patients during pregnancy, delivery and puerperium underscores the need for special care during ante partum, intrapartum and postpartum period Ahmed et al., (2012). Regardless the elevated risk of maternal and neonatal complications among multiparty, recent studies proved that they had little risk with adequate antenatal care Ahmed et al., (2012).

The aim of the study:

The aim of the study was to determine the effects of antenatal care on maternal and neonatal outcomes 
Research questions:

What are the effects of both antenatal care and parity on maternal and neonatal outcomes?

Subjects and method:

Research design: It was comparative descriptive study.

Setting: The setting of this study was the postpartum unit of Women Health Hospital in Assiut University during the period from February 2017 to August 2017.

\section{Sample:}

The study included the stratified sample of 300 parous women and their neonates. They were divided into two groups' according to parity the first group (primipara $=150$ ), and the second group (high parity=150) and divided every group into two groups the first was poor antenatal care and other was adequate antenatal care. Mothers who attend $\geq 4$ visits considered adequate antenatal care and those attend $<4$ visits were considered poor antenatal care. Neonates were born to the participants within 24 hours of birth.

\section{Tools:}

Interview sheet was designed by the investigator to collect data related to demographic characteristics, medical history, obstetric history, antenatal care pattern, current obstetric history, maternal outcomes and neonatal outcomes.

The interviewing data that was collected by the investigator included:

- Personal history: name, age, residents, educational level and occupation

- Medical history: included specific historical diseases and conditions as Hypertension, diabetes mellitus, heart diseases and chronic renal disease.

- The pattern of antenatal care: First antenatal visit, the frequency of antenatal visits, place of antenatal visit and reason of it, barriers for antenatal care.

- The current obstetric history: Last menstrual period and expected date of delivery

- Maternal outcome: Obstetric complications of current pregnancy, mode of delivery, complications of the present labor if present.

- Neonatal outcomes: (Preterm birth, post-term birth, low birth weight, stillbirth, special care birth unit admission, and neonatal weight in Kilogram).

Method of data collection:

- A review of national and international related literature of the current study using textbooks, articles, and scientific journals was done, and to be able to design the data collection forms. Then, the tools were prepared and reviewed by experts in nursing and medicine to ascertain their content validity.

- Before starting this study an official permission was obtained from the head of the Department of Obstetrics and Gynecology in Women Health Hospital in Assuit University after explaining the aim of the study.

- A pilot study was carried out on 30 postpartum women divided into 15 primiparity \& 15 high parity to test the clarity of the questions and to detect any further problems or difficulties that help in making the necessary modification. There wasn't any modification on the tool and the pilot sample was included in the total sample.

- The study was carried out during the period from February 2017 to August 2017 for six months twice weekly every visit we take 6-7 woman in the day.

- Each woman was interviewed to fill the study tools and to assess antenatal care attendance data and barriers for antenatal care after explaining the 
aim and nature of the study to them.

- Then fill neonatal outcomes tools to the participants to assess neonatal complication and compared between primipara and high parity versus poor antenatal care and adequate antenatal care.

- Neonatal weight measured to determined low birth weight and its relation to antenatal care.

\section{Ethical considerations:}

The research proposal was approved by Ethical Committee in the Faculty of Nursing. No risk for study subjects during application of the research. Oral consent was taken from each woman to participate in this study. Confidentiality and anonymity were obtained and women privacy was assured during collection of data.

\section{Statistical design}

Data entry and statistical analysis were done using the statistical package for social science program (SPSS. version 23). Qualitative variables were presented as the number, percentage, and frequency. Quantitative variables were presented as mean \pm SD. Comparison between qualitative variables was done by using chi-square. Comparison between quantitative variables was done by using one way a nova test and independent test. A significance level was considered at $P<0.05$.

\section{Results}

In the table (1): there is the significant relationship between high parity (multipara\& grand multipara) and primiparity women related to age more than half of primipara age less than 25 years $(66.7 \%)$ but less than half of high parity $(36.5 \%)$ age range from (25-29 years). Regarding the level of education, there are significant relations less than half of primiparity was highly educated $(49.3 \%)$ less than half of the high parity $(38.5 \%)$ are illiterate.
Table (2) \& Figure (1): There were the significant relationship between primigravida and multigravida regarding antenatal care, $(88.0 \%)$ of primiparity number antenatal visit (poor ANC $<4$ visits) times but in high parity $(67.3 \%)$ more than four times. Eighty percent from primiparity follow up for tetanus toxoid but high parity $(64.7 \%)$ come for the antenatal visit for follow up.

Table (3): About eighty-seven percent in primiparity had significant barrier in antenatal care but $(89.9 \%)$ in high parity had no barrier for antenatal care but the common barrier (44\%) is inability to afford cost of antenatal care in primiparity but the common barrier $(7.3 \%)$ was distance in high parity.

Figure (2): The majority of primiparous women deliver normally (74.8\%) but the majority of high parity women $(74.8 \%)$ deliver by cesarean section.

Table (4): Shows prenatal complications and antenatal care among two groups. The complications in the primiparity group were $(69.7 \% ; 22.2 \%)$ in poor ANC; and adequate ANC respectively. But in high parity group were $(44.9 \% ; 45.5 \%)$ in poor ANC and adequate ANC respectively. The most common complication in the primiparity group was eclampsia $(36.4 \%)$ in poor ANC. While in high parity group was anemia $(14.3 \%)$ in poor ANC. The complications of pregnancy outcome in the primiparity group were $(22.0 \%$; $11.1 \%$ ) in poor $\mathrm{ANC}$; and adequate $\mathrm{ANC}$ respectively. But in high parity group were $(46.9 \% ; 44.6 \%)$ in poor ANC and adequate ANC respectively. The most common complication in labor was premature rupture of membrane (PROM) $(19.0 \% \& 14.3 \%)$ respectively, in poor ANC of two groups.

Table (5): Show that The most common complication in the prenatal were eclampsia and anemia (48.6\%; 
$23.4 \%$ ) respectively in poor ANC but inadequate $\mathrm{ANC}$ was eclampsia $(36.6 \%)$ there was highly significant relationship between antenatal care and maternal complication $\mathrm{p}<0.000$ while the most common complication in the perinatal \& postnatal was PROM (33.3\%) in poor ANC but inadequate ANC was obstructed labor $(20.5 \%)$ there was highly significant relationship between antenatal care and maternal complication $\mathrm{p}<0.000$.

Table (6): Show that neonatal complication were $(\mathbf{5 5 . 0 \%} \& \mathbf{2 2 . 2 \%})$ in poor ANC; and adequate ANC respectively, there were highly significant $(\mathrm{p}<0.002 * *)$. The most common complication in the newborn outcome was (low birth weight), (stillbirth), (preterm baby) and (low birth weight, Special Care Baby Units admission) $(7.6 \% ; 5.7 \% ; 4.6 \% ; 4.0 \%)$ respectively in poor ANC but inadequate ANC was SCBU admission (4.0\%). The means and standard deviation of neonatal weight related to poor ANC and adequate ANC were $(2.72 \pm .684 \& 3.08$ \pm .622) respectively there was highly significant relationship $\mathrm{P}=.000 * *$

Table (7): Shows highly significant relationship between two groups regarding neonatal birth outcome complication. The complications of neonatal outcome in the primiparity group were $(55.0 \% ; 22.2 \%)$ in poor ANC; and adequate ANC respectively. But in high parity group were $(43.9 \%$; $32.7 \%$ ) in poor ANC and adequate ANC respectively. In the primiparity group, the proportion of low birth weight; Stillbirth; LBW \& SCBU admission and preterm were $16.0 \%$; 9.9\%; 9.2\%; $8.4 \%$ in poor ANC respectively, while stillbirth was $(11.0 \%)$ inadequate ANC. In high parity group, the proportion of SCBU admission \& Stillbirth were $12.2 \% \& 9.8 \%$ in poor ANC respectively. While SCBU admission was $11.9 \%$ inadequate $\mathrm{ANC}$. In the primiparity group, the means and standard deviation of neonatal weight related to poor ANC and adequate ANC were $(2.636 \pm 0.659 \& 3.050 \pm 0.503)$ respectively there was highly significant relationship $\mathrm{P}=0.001 * *$. While in high parity group the means and standard deviation of neonatal weight related to poor ANC and adequate ANC were $(2.973 \pm 0.709 \quad \& \quad 3.081 \quad \pm .643)$ respectively there was no significant relationship $\mathrm{P}=0.613$

Table (1): Comparison between primiparity and high parity groups regarding demographic data $(n=300)$ 
EFFECT OF ANTENATAL CARE ON MATERNAL AND etc...

\begin{tabular}{|c|c|c|c|c|c|}
\hline \multirow{2}{*}{ Variables } & \multicolumn{2}{|c|}{ Primiparity } & \multicolumn{2}{|c|}{ High parity } & \multirow[t]{2}{*}{ p.value } \\
\hline & $\mathbf{N}=\mathbf{1 5 0}$ & $\%$ & $\mathrm{~N}=150$ & $\%$ & \\
\hline \multicolumn{5}{|l|}{ Age groups } & \\
\hline Less than 25 years & 103 & 68.7\% & 41 & $27.3 \%$ & \multirow[t]{4}{*}{$0.00 * *$} \\
\hline From $25-29$ years & 34 & $22.4 \%$ & 54 & $36.5 \%$ & \\
\hline From 30-34 years & 12 & $7.9 \%$ & 20 & $13.5 \%$ & \\
\hline From 30-or more & 1 & $0.7 \%$ & 35 & $23.6 \%$ & \\
\hline \multicolumn{5}{|l|}{ Level of education } & \\
\hline Illiterate & 30 & $19.7 \%$ & 57 & $38.5 \%$ & \multirow[t]{5}{*}{$0.00 * *$} \\
\hline Read and write & 2 & $1.3 \%$ & 10 & $6.8 \%$ & \\
\hline Basic education & 6 & $4.0 \%$ & 13 & $8.7 \%$ & \\
\hline Secondary school & 38 & $25.0 \%$ & 51 & $34.5 \%$ & \\
\hline high education & 74 & $49.3 \%$ & 19 & $12.7 \%$ & \\
\hline \multicolumn{5}{|l|}{ Occupation } & \\
\hline Employee & 1 & $0.7 \%$ & 17 & $11.3 \%$ & \multirow[t]{2}{*}{$0.00 * *$} \\
\hline Housewife & 149 & $99.3 \%$ & 133 & $88.7 \%$ & \\
\hline \multicolumn{5}{|l|}{ Address } & \\
\hline Urban & 19 & $12.7 \%$ & 37 & $24.7 \%$ & \multirow[t]{2}{*}{$0.00 * *$} \\
\hline Rural & 131 & $\mathbf{8 7 . 3 \%}$ & 113 & $75.3 \%$ & \\
\hline \multicolumn{6}{|l|}{ Husband education } \\
\hline Illiterate & 32 & $21.3 \%$ & 39 & $26.0 \%$ & \multirow[t]{5}{*}{$0.00 * *$} \\
\hline Read and write & 0 & $0.0 \%$ & 21 & $14.0 \%$ & \\
\hline Basic education & 5 & $3.3 \%$ & 15 & & \\
\hline Secondary school & 32 & $21.3 \%$ & 54 & $36.0 \%$ & \\
\hline high education & 81 & $54.0 \%$ & 21 & $14.0 \%$ & \\
\hline
\end{tabular}

Statistical significant difference $\mathrm{P} \leq 0.05$

** highly significant difference

* significant difference

Table (2): Comparison between primiparity and high parity groups regarding the pattern of antenatal care $(\mathrm{n}=300)$

\begin{tabular}{|c|c|c|c|c|c|}
\hline \multirow{2}{*}{ Variables } & \multicolumn{2}{|c|}{ primiparity } & \multicolumn{2}{|c|}{ High parity } & \multirow[t]{2}{*}{ p.value } \\
\hline & $\mathrm{N}=150$ & $\%$ & $\mathrm{~N}=150$ & $\%$ & \\
\hline \multicolumn{5}{|c|}{ Times of first antenatal visit } & \\
\hline $\begin{array}{l}\text { First semester }\left(1^{\text {st }} \text { to } 3^{\text {rd }}\right. \\
\text { months })\end{array}$ & 72 & $48.0 \%$ & 109 & $72.7 \%$ & \multirow[t]{5}{*}{$0.01 *$} \\
\hline $\begin{array}{l}\text { Second semester }\left(4^{\text {th }} \text { to } 6^{\text {th }}\right. \\
\text { months })\end{array}$ & 33 & $22.0 \%$ & 19 & $12.7 \%$ & \\
\hline $\begin{array}{l}\text { Third semester(7th to 9th } \\
\text { months) }\end{array}$ & 44 & $29.3 \%$ & 13 & $8.7 \%$ & \\
\hline \multicolumn{5}{|c|}{ The reason for the antenatal care } & \\
\hline Follow up & 20 & $13.3 \%$ & 97 & $64.7 \%$ & \\
\hline $\begin{array}{l}\text { Treating problem from } \\
\text { pregnancy }\end{array}$ & 9 & $6.0 \%$ & 39 & $26.0 \%$ & \multirow[t]{2}{*}{0.002} \\
\hline $\begin{array}{l}\text { Tetanus Toxoid } \\
\text { immunization }\end{array}$ & 120 & $80.0 \%$ & 5 & $3.3 \%$ & \\
\hline
\end{tabular}


Figure (1): Comparison between primiparity and high parity group regarding the pattern of antenatal care $(n=300)$

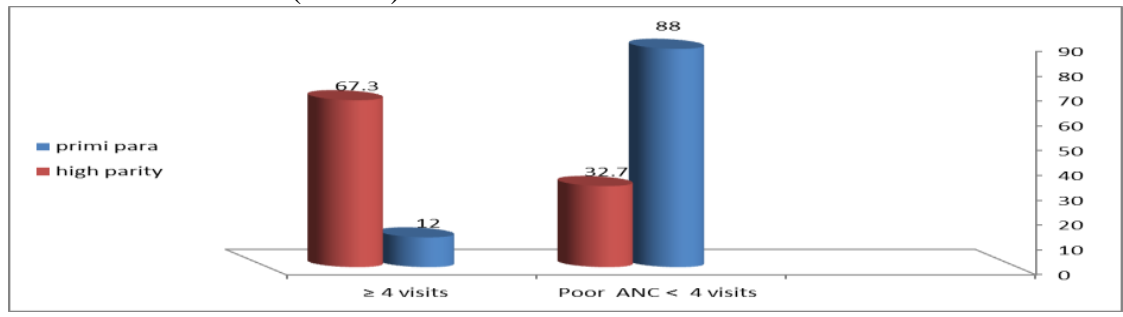

Table 3: Comparison between primiparity and high parity group regarding barriers to antenatal care $(\mathrm{n}=300)$

\begin{tabular}{|c|c|c|c|c|c|}
\hline \multirow{2}{*}{ Variables } & \multicolumn{2}{|c|}{ primary Para } & \multicolumn{2}{|c|}{ High parity } & \multirow[b]{2}{*}{ p.value } \\
\hline & $\mathrm{N}=150$ & $\%$ & $N=150$ & $\%$ & \\
\hline \multicolumn{5}{|c|}{ Barriers to antenatal care } & \\
\hline Present & 130 & $86.7 \%$ & 15 & $10.1 \%$ & \multirow[t]{2}{*}{$0.00 * *$} \\
\hline Not present & 20 & $13.3 \%$ & 135 & $89.9 \%$ & \\
\hline \multicolumn{5}{|l|}{ Types of barriers } & \multirow{7}{*}{$0.00 * *$} \\
\hline Distance & 0 & $0.0 \%$ & 11 & $7.3 \%$ & \\
\hline $\begin{array}{l}\text { Transportation } \\
\text { dilemma }\end{array}$ & 0 & $0.0 \%$ & 2 & $1.3 \%$ & \\
\hline $\begin{array}{l}\text { Inability to afford } \\
\text { the cost of } \\
\text { antenatal care }\end{array}$ & 66 & $44.0 \%$ & 1 & $0.7 \%$ & \\
\hline family opposed & 8 & $5.3 \%$ & 0 & $0.0 \%$ & \\
\hline $\begin{array}{l}\text { Lack of awareness } \\
\text { about the importance } \\
\text { of antenatal care }\end{array}$ & 22 & $14.7 \%$ & 0 & $0.0 \%$ & \\
\hline Other & 34 & $22.7 \%$ & 1 & $0.7 \%$ & \\
\hline
\end{tabular}

Table 4: Comparison between pregnancy complications and number of antenatal visits in two groups $(n=300)$

\begin{tabular}{|c|c|c|c|c|c|c|c|c|c|}
\hline \multirow{3}{*}{$\begin{array}{l}\text { maternal } \\
\text { complication }\end{array}$} & \multicolumn{4}{|c|}{$\begin{array}{l}\text { number of antenatal care in } \\
\text { primiparity }\end{array}$} & \multicolumn{4}{|c|}{$\begin{array}{l}\text { number of antenatal care in high } \\
\text { parity }\end{array}$} & \multirow{3}{*}{$\begin{array}{l}\text { p. } \\
\text { value }\end{array}$} \\
\hline & \multicolumn{2}{|c|}{$<4$ visits } & \multicolumn{2}{|c|}{$\geq 4$ visits } & \multicolumn{2}{|c|}{$P<4$ visits } & \multicolumn{2}{|c|}{$\geq 4$ visits } & \\
\hline & $\mathrm{N}=132$ & $\%$ & $\mathrm{~N}=18$ & $\%$ & $\mathrm{~N}=49$ & $\%$ & $\mathrm{~N}=101$ & $\%$ & \\
\hline $\begin{array}{l}\text { No } \\
\text { complications }\end{array}$ & 40 & $30.3 \%$ & 14 & $77.8 \%$ & 27 & $55.1 \%$ & 55 & $54.5 \%$ & $0.00 * *$ \\
\hline complications & 92 & $69.7 \%$ & 4 & $22.2 \%$ & 22 & $44.9 \%$ & 46 & $45.5 \%$ & \\
\hline $\begin{array}{l}\text { Gestational } \\
\text { diabetes }\end{array}$ & 12 & $9.1 \%$ & $\mathbf{0}$ & $0.0 \%$ & 0 & $0.0 \%$ & 2 & $2.0 \%$ & \\
\hline Preeclampsia & 0 & $0.0 \%$ & 0 & $0.0 \%$ & 1 & $2.0 \%$ & 2 & $2.0 \%$ & \\
\hline Eclampsia & 48 & $36.4 \%$ & 3 & $16.6 \%$ & 6 & $12.2 \%$ & 20 & $20.0 \%$ & \\
\hline Anemia & 12 & $9.1 \%$ & 1 & $5.6 \%$ & 7 & $14.3 \%$ & 10 & $9.8 \%$ & \\
\hline $\begin{array}{l}\text { Poly } \\
\text { hydrominos }\end{array}$ & 4 & $3.0 \%$ & 0 & $0.0 \%$ & 1 & $2.0 \%$ & 3 & $3.0 \%$ & \\
\hline $\begin{array}{l}\text { Antepartum } \\
\text { hemorrhage }\end{array}$ & 2 & $1.5 \%$ & 0 & $0.0 \%$ & 5 & $10.2 \%$ & 7 & $6.8 \%$ & \\
\hline Others & 14 & $10.6 \%$ & 0 & $0.0 \%$ & 2 & $4.1 \%$ & 2 & $2.0 \%$ & \\
\hline
\end{tabular}




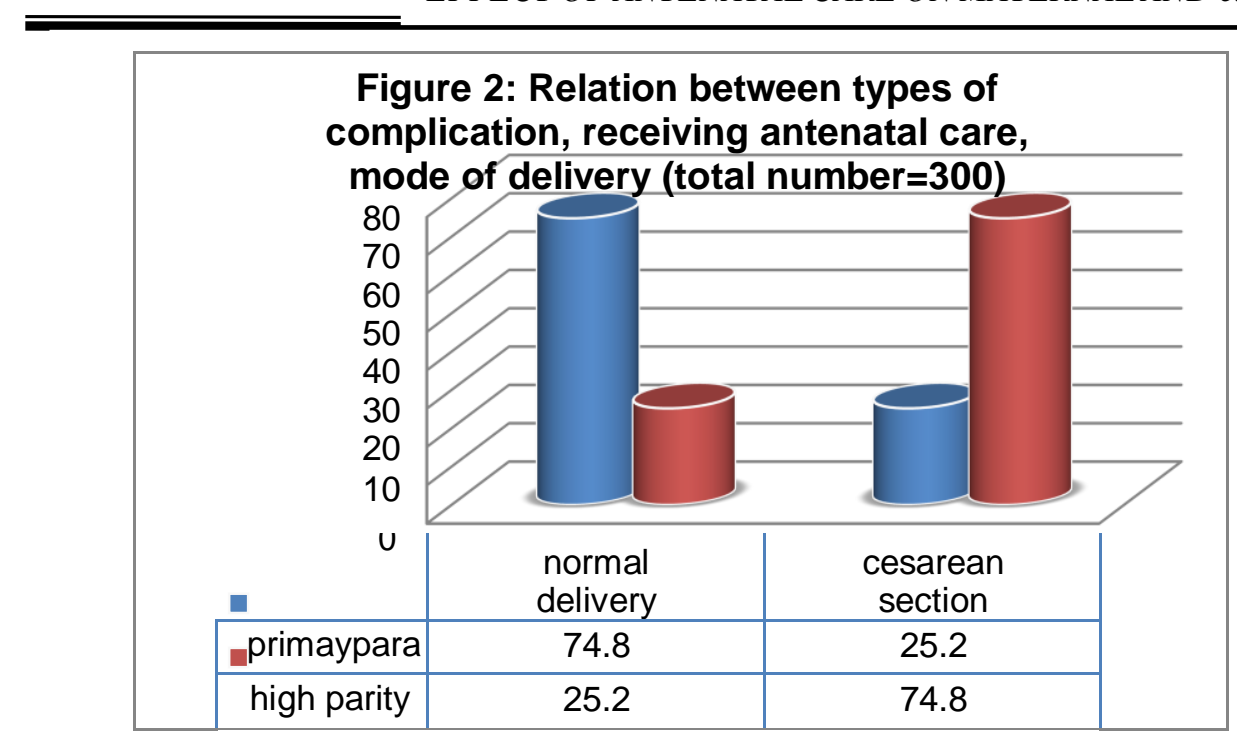

Table 5: Comparison between number of antenatal visits and pregnancy outcome $(n=300)$

\begin{tabular}{|c|c|c|c|c|c|c|c|c|c|}
\hline \multirow{3}{*}{$\begin{array}{l}\text { pregnancy } \\
\text { complication }\end{array}$} & \multicolumn{4}{|c|}{$\begin{array}{l}\text { number of antenatal visits in } \\
\text { primiparity }\end{array}$} & \multicolumn{4}{|c|}{$\begin{array}{l}\text { number of antenatal visits in high } \\
\text { parity }\end{array}$} & \multirow[t]{3}{*}{ p. value } \\
\hline & \multicolumn{2}{|c|}{$<4$ visits } & \multicolumn{2}{|c|}{$\geq 4$ visits } & \multicolumn{2}{|c|}{$P<4$ visits } & \multicolumn{2}{|c|}{$\geq 4$ visits } & \\
\hline & $\mathrm{N}=132$ & $\%$ & $\mathrm{~N}=18$ & $\%$ & $N=49$ & $\%$ & $\mathrm{~N}=101$ & $\%$ & \\
\hline $\begin{array}{l}\text { Non } \\
\text { complication }\end{array}$ & 103 & $78.0 \%$ & 16 & $88.9 \%$ & 26 & $53.0 \%$ & 56 & $55.4 \%$ & \multirow{7}{*}{$0.001^{* *}$} \\
\hline complication & 29 & $22.0 \%$ & 2 & $11.1 \%$ & 23 & $46.9 \%$ & 45 & $44.6 \%$ & \\
\hline PROM & 25 & $19.0 \%$ & 1 & $5.6 \%$ & 7 & $14.3 \%$ & 12 & $11.9 \%$ & \\
\hline $\begin{array}{l}\text { Prolonged } \\
\text { labor }\end{array}$ & & $0.0 \%$ & 0 & $0.0 \%$ & 4 & $8.2 \%$ & 4 & $4.0 \%$ & \\
\hline $\begin{array}{l}\text { Obstructed } \\
\text { labor }\end{array}$ & 3 & $2.3 \%$ & 1 & $5.6 \%$ & 2 & $4.0 \%$ & 15 & $14.9 \%$ & \\
\hline $\begin{array}{l}\text { Postpartum } \\
\text { hemorrhage }\end{array}$ & 0 & $0.0 \%$ & 0 & $0.0 \%$ & 4 & $8.2 \%$ & 3 & $3.0 \%$ & \\
\hline Other & 1 & $0.8 \%$ & 0 & $0.0 \%$ & 6 & $12.2 \%$ & 11 & $10.9 \%$ & \\
\hline
\end{tabular}

Table 6: Comparison between antenatal care and neonatal outcome $\quad(n=300)$

\begin{tabular}{|c|c|c|c|c|c|}
\hline \multirow{3}{*}{ Neonatal complication } & \multicolumn{4}{|c|}{ number of antenatal care } & \multirow[t]{3}{*}{ p. value } \\
\hline & \multicolumn{2}{|c|}{$<4$ visits } & \multicolumn{2}{|c|}{$\geq 4$ visits } & \\
\hline & $\mathrm{N}=181$ & $\%$ & $\mathrm{~N}=119$ & $\%$ & \\
\hline No complications & 88 & $29.4 \%$ & 82 & $27.3 \%$ & \multirow{11}{*}{$0.002 * *$} \\
\hline Complications & 75 & $55 \%$ & 4 & $22.2 \%$ & \\
\hline Preterm birth & 14 & $4.6 \%$ & 8 & $2.7 \%$ & \\
\hline Stillbirth & 17 & $5.7 \%$ & 9 & $3.0 \%$ & \\
\hline Post-term birth & 1 & $0.3 \%$ & 1 & $0.3 \%$ & \\
\hline LBW & 23 & $7.6 \%$ & 3 & $1.0 \%$ & \\
\hline Neonatal death & 3 & $1.0 \%$ & 3 & $1.0 \%$ & \\
\hline SCBU admission & 9 & $3.0 \%$ & 12 & $4.0 \%$ & \\
\hline LBW and SCBU admission & 12 & $4.0 \%$ & 0 & $0.0 \%$ & \\
\hline Preterm birth and LBW & 6 & $2.0 \%$ & 1 & $0.3 \%$ & \\
\hline $\begin{array}{l}\text { Preterm birth and LBW and } \\
\text { SCBU admission }\end{array}$ & 8 & $2.7 \%$ & 0 & $0.0 \%$ & \\
\hline Neonatal weight $($ means \pm SD) & \multicolumn{2}{|c|}{$2.72 \pm 0.684$} & \multicolumn{2}{|c|}{$3.08 \pm 0.622$} & $0.000^{* * *}$ \\
\hline
\end{tabular}


Table (7): Comparison between number of antenatal visits and neonatal birth outcome in two groups $(n=300)$

\begin{tabular}{|c|c|c|c|c|c|c|c|c|c|}
\hline \multirow[t]{3}{*}{$\begin{array}{l}\text { Neonatal } \\
\text { outcome }\end{array}$} & \multicolumn{4}{|c|}{$\begin{array}{l}\text { number of antenatal care in } \\
\text { primiparity }\end{array}$} & \multicolumn{4}{|c|}{$\begin{array}{l}\text { number of antenatal care in high } \\
\text { parity }\end{array}$} & p. value \\
\hline & \multicolumn{2}{|c|}{$<4$ visits } & \multicolumn{2}{|c|}{$\geq 4$ visits } & \multicolumn{2}{|c|}{$\mathrm{P}<4$ visits } & \multicolumn{2}{|c|}{$\geq 4$ visits } & \multirow{14}{*}{$0.00 * *$} \\
\hline & $\mathrm{N}=132$ & $\%$ & $\mathrm{~N}=18$ & $\%$ & $\mathrm{~N}=49$ & $\%$ & $\mathrm{~N}=101$ & $\%$ & \\
\hline $\begin{array}{l}\text { No } \\
\text { complications }\end{array}$ & 57 & $43.5 \%$ & 14 & $77.8 \%$ & 31 & $75.6 \%$ & 68 & $67.3 \%$ & \\
\hline complications & 75 & $55 \%$ & 4 & $22.2 \%$ & 18 & $43.9 \%$ & 33 & $32.7 \%$ & \\
\hline Preterm birth & 11 & $8.4 \%$ & $\mathbf{0}$ & $0.0 \%$ & 3 & $7.3 \%$ & 8 & $7.9 \%$ & \\
\hline Stillbirth & 13 & $9.9 \%$ & 2 & $11.0 \%$ & 4 & $9.8 \%$ & 7 & $6.9 \%$ & \\
\hline $\begin{array}{l}\text { Post term } \\
\text { birth }\end{array}$ & 0 & $0.0 \%$ & 0 & $0.0 \%$ & 1 & $2.4 \%$ & 1 & $1.0 \%$ & \\
\hline LBW & 21 & $16.0 \%$ & 1 & $5.6 \%$ & 2 & $4.9 \%$ & 2 & $2.0 \%$ & \\
\hline $\begin{array}{l}\text { Neonatal } \\
\text { death }\end{array}$ & 0 & $0.0 \%$ & 0 & $0.0 \%$ & 3 & $7.3 \%$ & 3 & $3.0 \%$ & \\
\hline $\begin{array}{l}\text { SCBU } \\
\text { admission }\end{array}$ & 4 & $3.1 \%$ & 0 & $0.0 \%$ & 5 & $12.2 \%$ & 12 & $11.9 \%$ & \\
\hline $\begin{array}{l}\text { LBW and } \\
\text { SCBU } \\
\text { admission }\end{array}$ & 12 & $9.2 \%$ & 0 & $0.0 \%$ & 0 & $0.0 \%$ & 0 & $0.0 \%$ & \\
\hline $\begin{array}{l}\text { Preterm birth } \\
\text { and LBW }\end{array}$ & 6 & $4.6 \%$ & 1 & $5.6 \%$ & 0 & $0.0 \%$ & 0 & $0.0 \%$ & \\
\hline $\begin{array}{l}\text { Preterm birth } \\
\text { and } L B W \text { and } \\
\text { SCBU } \\
\text { admission }\end{array}$ & 8 & $6.1 \%$ & 0 & $0.0 \%$ & 0 & $0.0 \%$ & 0 & $0.0 \%$ & \\
\hline p. value & \multicolumn{4}{|c|}{0.070} & \multicolumn{4}{|c|}{0.707} & \\
\hline $\begin{array}{l}\text { Neonatal } \\
\text { weight }(\text { Kgm) } \\
(\text { means } \pm \text { SD })\end{array}$ & \multicolumn{2}{|c|}{$2.636 \pm .659$} & \multicolumn{2}{|c|}{$3.050 \pm 0.503$} & \multicolumn{2}{|c|}{$2.973 \pm .709$} & \multicolumn{2}{|c|}{$3.081 \pm 0.643$} & \multirow[t]{2}{*}{$0.000^{* * * *}$} \\
\hline p. value & \multicolumn{4}{|c|}{$0.001^{* * *}$} & \multicolumn{4}{|c|}{0.613} & \\
\hline
\end{tabular}

\section{Discussion}

Approximately 303,000 women died from pregnancy and childbirth-related complications in 2015 Alkema, Chou, Hogan, Zhang, Moller, Gemmill (2016). That same year, 2.6 million babies were stillborn. Almost all of the maternal deaths $(99 \%)$ and child deaths $(98 \%)$ occurred in inadequate - and moderate-income countries. These maternal deaths could have been prevented if the pregnant women had been able to access quality antenatal care (ANC) WHO (2018). Various adverse maternal factors were associated with very low birth weight and their morbidities. The identification of adverse maternal factors and its appropriate management can lead to the better outcome of the baby Patki, \& Antin (2017). So the purpose of prenatal care is to decrease the number of infants born too soon (preterm birth), too small (low birth weight) and to prevent mother and infant sickness and death Ziyo, Matly, Mehemd, Dofany (2009).

The current study determines the effects of antenatal care on maternal and neonatal outcomes in different parity status.

In the present study, we found that more than half of primiparity age less than 25 Yrs $(66.7 \%)$ but less than half of high parity (multipara\& grand multipara)(36.5\%)age range from (25-29 Yrs). The similar finding was Corroborated by Baruah C (2016) who found that majority $(52 \%)$ of primiparous were in 21-25 years age group and the majority $(55.3 \%)$ of multiparous were in 26-30 years age group which was statistically significant. Similar findings were corroborated by Jaspinder \& kawaljit (2012), who also found that majority $(51.92 \%)$ of primiparous mothers belonged to 21 $25 \mathrm{yrs}$ of age group and $35.41 \%$ of multiparous belonged to 26-30 yrs of the age group which was also statistically significant.

In our study regarding the level of education, there are significant relation less than half of primiparity are high education $(49.3 \%)$ less than half of the high parity is $(38.5 \%)$ are illiterate. These findings are in conformity with the results of Baruah C (2016) who found that $(30.8 \%$ \& $22.4 \%$ ) of primiparous and multiparous were illiterate. Only $28.8 \%$ of primiparous and $19.7 \%$ of multiparous was educated up to the high school level. Chandramouli C.( 2011) reported that women with less education are more vulnerable to health complications because of lack of knowledge regarding complications whereas educated women are more aware of the problems that might occur 
EFFECT OF ANTENATAL CARE ON MATERNAL AND etc...

during pregnancy and they are in a better position to take care of such problems.

In our study regarding antenatal care, $(88.0 \%)$ of primiparity number antenatal visit (poor ANC < 4 visits) times but in high parity $(67.3 \%)$ more than four times. Eighty percent from primiparity follow up for tetanus toxoid but high parity $(64.7 \%)$ attendance antenatal visit for follow up. Comparable if not similar finding Baruah $\mathbf{C}$ (2016) who found that, the majority $(59.6 \%)$ of primiparous and $55.3 \%$ of multiparous had 4 antenatal visits although the differences were not statistically significant. This is contrary to the findings reported by Jaspinder \& kawaljit, (2012) who found that where the majority of primiparous mothers $(67.30 \%)$ didn't approach for antenatal care, the greater part of multiparous women $(52.08 \%)$ booked themselves for the same $(\mathrm{p}<0.05)$.

In our study were eighty-seven percent the primiparity had a significant barrier in antenatal care but $(89.9 \%)$ in high parity had no barrier for antenatal care. The common barrier $(44 \%)$ is an inability to afford the cost of antenatal care in primiparity while the common barrier $(7.3 \%)$ was the distance in high parity.

Comparable if not similar Ishtiaque, Malik, Jadoon (2016) Some of the reasons for late bookings include the following: younger age, primigravida, multigravida, single parent, low socio-economic status, unemployment, time constraints and for some women, the distance from the healthcare facility are factors responsible for being unbooked. We conducted this study to compare the effect of parity on maternal and fetal outcomes versus antenatal care.

Also, Mugo et al (2015) in South Sudan reported that women living in urban areas more attend Antenatal care services, than women living in rural areas. The rationale for these results may be due to the distance to maternal health services and transportation dilemma may greatly reduce access to antenatal care services in rural areas.

Abbas et al., (2017) regarding the reasons for not attending ANC regularly, (44.6\%) of the mothers responded that they were unable to afford the cost of antenatal care and $(20 \%)$ of the mothers cited ignorance about the importance of antenatal care (responded that they were apparently healthy during the pregnancy) were the most stated reasons for not attending ANC regularly. These results agree with Dairo \& Owoyokun (2010) who reported that $(58.3 \%)$ gave the inability to afford the cost of antenatal care as the reason for not obtaining antenatal care at all. The same in the study of Mumbare \& Rege (2011) in India who reported that the main reasons for inadequate utilization of ANC services were financial, unawareness about ANC services. On the contrary, Abosse, Woldie \& Ololo (2011) reported that
$(65.3 \%)$ of the mothers responded that they were apparently healthy during their last pregnancy.

These findings are in conformity with results Ali \& AbdAlla (2016) reported that distance to the health facility significantly determined both the chance and frequency of attending Focused Antenatal Care (FANC) clinics. Long distance to the health facility is highly associated with fewer visits.

Comparable if not similar finding Roy, \& Vernekar (2017), reported that lack of antenatal care attendance since we documented $61.8 \%$, unbooked women. This is contrary to the findings reported by Ali \& AbdAlla (2016) reported that there is a direct relationship between parity and utilization of the ANC, with multiparous women making significantly fewer visits to ANC than primiparous women. This study finding proves the same result, that majority of participants utilizes ANC services $(86.5 \%)$ during their pregnancy because most of them are primigravida and in their first time.

We found that unbooked mothers had more postnatal complications like (anemia, puerperal pyrexia postpartum hemorrhage and wound infections) as compared to booked mothers. (35.5\% vs $0.5 \%$ ). Similar findings were reported in the study Tucker, Ogutu, Yoong, Nauta, and Fakokunde (2010).

In our study, the majority of primiparity women $(74.8 \%)$ normal delivery but the majority of high parity women $(74.8 \%)$ cesarean section delivery there is the highly significant relationship between two groups.

These finding in conformity with the results of Baruah (2016) study, who reported that prevalence of cesarean section in primiparity was $(69.2 \%)$ as compared to the prevalence of cesarean section in multiparous mothers $(56.6 \%)$ although the differences were not statistically significant. The similar finding was corroborated by Jaspinder \& Kawaljit (2012) who also found that incidence of emergency lower segment cesarean section (LSCS) in primiparous was $65.51 \%$ which was higher than the incidence of emergency LSCS in multiparous mothers $(41.66 \%)$ although the differences were not statistically significant. Cesarean sections have been long practiced as a lifesaving procedure for the mother and fetus. The incidence of cesarean section has risen considerably over the years and is done for even trivial indications. The advances in the field have reduced maternal mortality considerably. But the problem of maternal and fetal morbidity after cesarean section is high. In our study, only $30.8 \%$ of primiparous had the vaginal delivery as compared to $43.4 \%$ of multiparous that had the vaginal delivery. Comparable if not similar was reported by Jaspinder,\& Kawaljit (2012) who found that $44.23 \%$ of primiparous had the 
vaginal delivery as compared to $25.0 \%$ of multiparous that had the vaginal delivery.

In our study were prenatal complications and antenatal care among two groups. The complications in a primiparity group were $(69.7 \%$; $22.2 \%$ ) in poor ANC; and adequate ANC respectively. But in high parity group were $(44.9 \%$; $45.5 \%$ ) in poor ANC and adequate ANC respectively. The most common complication in a primiparity group was eclampsia $(36.4 \%)$ in poor ANC. While in high parity group was anemia $(14.3 \%)$ in poor ANC. Maybe due to Muslim countries where there are the large family norm and poor acceptance of family planning methods due to specific religious or cultural beliefs and poor socioeconomic condition of the patient.

But in the study of Tuladhar \& Dhal 2011 found that similar common complication in the poor antenatal group is anemia $23.3 \%$ but the inadequate antenatal group is $9.3 \%$ who support our study.

Baruah (2016) study, among the multiparous 59.2 $\%$ were anemic as compared to $(46.2 \%)$ among the Primiparous which was not statistically significant. Comparable if not similar findings were reported by Jaspinder \& Kawaljit (2012) who also found that $25.0 \%$ of multiparous were anemic as compared to $23.07 \%$ of the primiparous who were anemic which was also not statistically significant.

Majoko, Nyström, Munjanja, Mason, and Lindmark (2004) reported that prevalence of anemia at booking (hemoglobin $10.5 \mathrm{~g} / \mathrm{dl}$ ) was reduced in primiparous compared to multiparous women $(11.7 \%$ vs $16.8 \%$; p 0.001$)$. primiparous women were likely to book early ( 20 weeks) for antenatal care, have a higher number of visits (6) and fewer home births. primiparous women had the higher risk for low birth weight (RR 1.70; 95\% CI 1.36 - 2.13). Compared to low parity women, primiparous and high parity women had an elevated risk of hypertensive complications RR 1.62 (95\% CI 1.37-1.92) and RR 1.64 (95\% CI 1.29 - 2.07) respectively. The risk of developing any pregnancy complications was highest in primiparous women (RR 1.48; 95\% 1.31- 1.67). In conclusion, primiparous women had an increased risk of pregnancy complications. High parity women with no previous complicated pregnancy were at low risk of complications.

In our study, we found the most common complication in the prenatal was eclampsia and anemia $(\mathbf{4 8 . 6 \%} ; \mathbf{2 3 . 4 \%})$ respectively in poor ANC but inadequate ANC was eclampsia (36.6\%). Conformity with Chigbu et al (2009) reported that increased incidence of antepartum hemorrhage, pre-eclampsia, and eclampsia in unbooked mothers. On another hand in our study, we found the most common complication in the perinatal \& postnatal was PROM $(33.3 \%)$ in poor ANC but inadequate ANC was obstructed labor $\mathbf{2 0 . 5 \% )}$

Taner, Ekin, Solmaz, Gezer, Çetin, Kelesoglu (2015) were conformity with my study who found that the prevalence of anemia at the time of delivery of $25 \%$ in his study. Polite et al. (2017) were conformity with my study who found that the prevalence of anemia was high $(56.7 \%)$ among the unbooked but lowest $(9.5 \%)$ with moderate attendees. Thereafter, there was no significant improvement. Delivery mode and gestational age at delivery were fairly uniform in all the groups. On the conformity, Ishtiaque, et al (2016) who found that the percentage of unbooked patients that had gone into obstructed labor was $4.0 \%$ and $1.5 \%$ of booked patients developed obstructed labor.

In our study, we found the most common complication anemia and postpartum hemorrhage $(\mathbf{2 3 . 4 \%} ; \mathbf{8 . 2 \%})$ respectively in poor ANC but inadequate ANC was $(\mathbf{1 5 . 4} \% \mathbf{3} . \mathbf{3} \%)$ respectively into groups.

These findings are in conformity with the results of Ishtiaque, et al (2016) who found that unbooked mothers had more postnatal complications like (anemia and postpartum hemorrhage) as compared to booked mothers. $(35.5 \%$ vs $0.5 \%)$. A similar finding was reported in the study by Tucker et al., (2010).

Ziyo et al., (2009) confirm our study who found that mothers who had no PNC had more complications like hypertension and postpartum hemorrhage $(16.7 \%)$ as compared to those registered before or at 16 weeks $(11.9 \%)$. Also $88.1 \%$ of healthy mothers registered before or at 16 weeks as compared to $83.3 \%$ of those who had no PNC.

In our study, in the primiparity group, the proportion of low birth weight was $16.0 \%$ in poor ANC, while stillbirth was $(11.0 \%)$ inadequate ANC.

These results agree with Abbas et al., (2017) who reported that there was the statistical significant difference between the neonatal outcomes in regular and irregular ANC primiparity groups with for better outcomes in all aspects in the regular ANC group with $(\mathrm{p}=0.000)$. These results agree with that of Ahmed et al., (2012), in Pakistan who reported that women with more than four antenatal visits were six times as likely to deliver normal weight babies. Also, these results agree with Raatikainen, Heiskanen, Heinonen (2010), who reported that there were significantly more low birth weight infants in under- and non-attenders, more fetal deaths, and more neonatal deaths.

In our study, we found that the neonates of the high parity had preterm and much more needs to have neonatal intensive care than primiparity $s$ in poor antenatal care and adequate antenatal care. Comparable if not similar finding Bezircioglu, 
Goral1, Baloglu, Baydar (2013) who found that the infants of the grand multipara had lower birth weight and much more needs to have neonatal intensive care than primiparas due to the grand multipara women who received lesser antenatal care. So she had more stillbirth, twin and preeclampsia history compared to the primipara. These findings are in contrary with Baruah (2016) Incidence rate of $2.6 \%$, still, birth and LBW babies were higher in Multigravida as compared to Primigravida.

In our study we found that neonatal complication was $(\mathbf{5 5 . 0 \%} \& \mathbf{2 2 . 2 \%})$ in poor antenatal care; and adequate ANC respectively, there were highly significant $\left(\mathrm{p}<0.002^{* *}\right)$. The most common complication in the neonatal outcome was (low birth weight), (stillbirth), (preterm birth) and (low birth weight, Special Care Baby Unit admission) $(7.6 \% ; 5.7 \% ; 4.6 \% ; 4.0 \%)$ respectively in poor ANC but inadequate ANC was Special Care Baby Unit admission (4.0\%).

Gupta \& Talukdar (2017) conformity with our study their results explain significant association between mothers receiving ANC 4-9 visits had experienced a lower risk of neonatal mortality. Mothers who received antenatal care visit from the first trimester experienced least pregnancy outcomes and neonatal deaths. Another study uniformly agrees with our finding Chingle, Bupwatda, Jonah, Zoakah (2017) was conformity with our study who found that the statistically significant association exists between antenatal care and baby's birth outcome, as well as between antenatal care and baby's birth weight.

These findings are conformity with the results of Ishtiaque, et al., (2016) who found that the unbooked mothers had the higher incidence of intrauterine deaths and low birth weight as compared to booked mothers. Around $40 \%$ of the neonates born to unbooked mothers ended up in $\mathrm{NCU}$ or neonatal death. P-value $=0.00$. Another study uniformly agrees with our findings Tucker et al., (2010); Osungbade \& Ayinde (2011). The unbooked mothers had the higher incidence of intrauterine deaths and low birth weight as compared to booked mothers. Around $40 \%$ of the neonates born to unbooked mothers ended up in NCU or neonatal death. Another study uniformly agrees with our finding Osungbade \& Ayinde (2011).

These finding in conformity with the results Polite, Ijeoma, Abimbola , Joel (2017) study, who found that the prevalence of low birth weight was $20 \%$ in the unregistered and decreased from $22 \%$ in the low frequency (1-3 visits) group to $4.8 \%$ in the moderate attendees, and to $0 \%$ in the very-highfrequency (ten and above visits) group. It also agrees with Tuladhar \& Dhakal (2011); Abbas et al., (2017) they were reported that the proportion of low birth weight and preterm babies was higher in women with inadequate or no antenatal care.

Special care baby unit admission was also higher among them due to various reasons like neonatal sepsis, birth asphyxia, jaundice etc. While there were no neonatal deaths during the study period, 3 stillbirths have occurred. Perinatal mortality rate was similar in no antenatal care and inadequate antenatal care groups; it was 16 times higher than that in the group with more than 4 visits. Maternal and perinatal outcomes were found to be better in women who attended regular antenatal care.

In our study, the means and standard deviation of neonatal weight related to poor antenatal care and adequate ANC were $(2.72 \pm$ $0.684 \& 3.08 \pm 0.622$ ) respectively there was highly significant relationship $\mathrm{P}=.000^{* *}$. There is the sharp reduction in the neonatal outcome was low birth weight $7.6 \%$ and $1 \%$ in poor antenatal care and adequate antenatal care respectively. Polite et al., (2017) support our study who found that there is sharp reduction in low birth weight from $22.6 \%$ in low-frequency group, to $4.8 \%$ in the moderate group, to $0 \%$ in the very high-frequency group might suggest that greater frequency of visits favors good birth weights, while the mean neonatal weight of $3.11 \mathrm{~kg}$ also compares with the $3.20 \mathrm{~kg}$ and $3.29 \mathrm{~kg}$ found elsewhere in Nigeria Osungbade,\& Ayinde (2011) it was improved by increasing antenatal visits, but there was no statistically significant difference found beyond 4 th- 6 th visit.

In the primiparity group, the means and standard deviation of neonatal weight related to poor antenatal care and adequate antenatal care were $(2.636 \pm 659 \& 3.050 \pm .503)$ respectively there was highly significant relationship $\mathrm{P}=0.001$

**. While in high parity group the means and standard deviation of neonatal weight related to poor antenatal care and adequate antenatal care were $(2.973 \pm .709 \& 3.081 \pm .643)$ respectively there was no significant relationship $\mathrm{P}=0.613$

This is contrary to the findings reported by Baruah (2016) study, who found that more than $(57.0 \%)$ low-birth-weight babies $(<2.5 \mathrm{Kgm})$ were born to multiparous as compared to primiparous $(20.0 \%)$ The high prevalence of LBW and neonatal special care unit admission in our study can be attributed to maternal eclampsia, poor antenatal care, and low education of the study subjects. Most $(59.6 \%$ and $55.3 \%$ ) of the primiparous and multiparous had four antenatal visits although the differences were not statistically significant.

Patki \& Antin (2017) confirm our study who found that majority $(81.82 \%)$ mothers of VLBW babies had adverse risk factors. Anemia, PROM $>=12$ hours and PIH were the commonest adverse maternal factors associated with very low birth weight babies. The majority (75.45\%) VLBW babies developed one or other kinds of morbidity. The commoner morbidity in VLBW was neonatal 
sepsis (30\%), RDS (19.09\%) and NNH (18.18\%).

The mortality in VLBW babies was only $21.81 \%$. RDS $(50 \%)$ was the commonest cause of death in VLBW, followed by sepsis $(16.6 \%)$. The mortality was highest in babies weighing less than 750 gram and less than 28 weeks of gestation. Both morbidity and mortality decreased significantly in babies with higher birth weight. APH, multiple pregnancy, and LSCS had the statistically significant association $(\mathrm{p}<0.001)$ with $\mathrm{RDS}$ in VLBW babies. Presence of PROM $>=12$ hours and maternal fever increased the risk of neonatal sepsis. Presence of PIH, abnormal presentation, multiple pregnancies and meconium staining of liquor were significantly associated with asphyxia.

\section{Conclusion:}

The study shows poor neonatal and maternal outcomes in primiparous women than among multiparous ones with the increase in maternal and neonatal complications among those with poor antenatal care.

\section{Recommendations:}

Based on the findings, the current study

recommended that:

1. Integrating community ANC outreach programmes in the national policy strategy and training geared towards early detection of complications can have positive implications for neonatal survival.

2. Health care providers should implement policies and design appropriate health education plans to reduce preventable neonatal complications.

3. Both the woman and the fetus are at a greater risk during pregnancy and labor. This risk can be effectively reduced with good antenatal care and delivery by trained personnel. As well as awareness of the adverse impact of high parity on obstetric performances should be intensified in our community.

4. Most high parity was of older age and poor socio-economic status. health education and use of contraception and good antenatal and intrapartum monitoring are needed.

\section{References:}

1.

bosse $Z$, Woldie $M$ \& Ololo S. (2011): Factors Influencing Antenatal Care Service Utilization in Hadiya Zone. Ethiop J Health Sci. 20(2).

2.

bbas M A, Ahmed H. N, Alam Eldin H and Ahmed R. M (2017): Impact of lack of antenatal care in primiparas on perinatal outcomes in Women Health Hospital, Assiut University. Thesis Submitted for partial fulfillment of the requirement of the Master's Degree in Obstetrics and Gynecological Nursing Science.
3. Ahmed Z, Khoja S \&Tirmizi SS. (2012):

Antenatal care and the occurrence of low birth weight delivery among women in the remote mountainous region of Chitral, Pakistan. Pak J Med Sci. 28(5):800-805

4. Ali H S \& AbdAlla A A (2016): Understand Factors Influencing Accessibility of Pregnant Women to Antenatal Care Services Vol.10 No.5:7 2016 () Copyright iMedPub

5. Alkema L, Chou D, Hogan D, Zhang $S$, Moller AB, Gemmill A, et al. (2016): Global, regional, and national levels and trends in maternal mortality between 1990 and 2015 , with scenario-based projections to 2030: a systematic analysis by the UN Maternal Mortality Estimation Inter-Agency Group. Lancet. 2016;387(10017):462-474. doi:10.1016/S0140-6736(15)00838-7.

6. Anavhe 0. (2015): Would Encourage women to attend antenatal visits help reduce maternal mortality in Nigeria? WORLD PLUS TAAF team: pregnant mother receives maternity pack https://www.worldpulse.com/en/community/us ers/odionanavhe/posts/36999 16-12-2017.

7. Baruah C (2016): A comparative study of obstetric complications among primigravida and multigravida attending labor room of a tertiary care hospital. Indian Journal of Basic and Applied Medical Research; September 2016: Vol.-5, Issue- 4, P. $147 \quad 153$ www.ijbamr.com P ISSN: 2250-284X, E ISSN: 2250-2858

8. Bezircioglu I, Goral1 $\mathbf{Y}$, Baloglu $\mathbf{A}$, Baydar Y (2013): The effect of grand multiparity on maternal, obstetric, fetal and neonatal outcomes. Perinatal Journal 2013;21(1):17-22

9. Bhat S \& Kulkarni V (2015): Study of Effect of Oligohydramnios on Maternal and Fetal Outcome January 2015 DOI: 10.19056/ ijmdsjssmes/ 2015/v4i1/ 79946

10. Chakraborty P, Anderson AK, (2011): $J$ Womens Health (Larchmt), 2011,20,1373.

11. Chandramouli $C$ (2011): Census of India. Provisional population totals, paper 1 of 2011 , India, Series 1. India: Office of Registrar General and Census Commissioner; 2011, p.

188.

Available

from:

http://www.censusindia.gov.in/2011provresults/ prov_results_paper1_india.html [cited 2 July 2012)

12. Chigbu B, Onwere S, Kamanu CI (2009): Pregnancy outcome in booked and unbooked mothers in South Eastern Nigeria. East Afr Med J. 2009;86(6):267-71

13. Chingle MP, Bupwatda, Jonah M. Zoakah A. I.(2017): Antenatal Care and Pregnancy Outcomes among Mothers Who Delivered in a Rural Hospital in Nigeria INTERNATIONAL JOURNAL OF INNOVATIVE RESEARCH 
\& DEVELOPMENT March 2017 Vol 6 Issue

3 www.ijird.com

14. 14 .

airo M D \& Owoyokun K. (2010): Factors affecting the utilization of antenatal care services in Ibadan, Nigeria. bump, 12(1):333.

15. El-Messidi A, \& Cameron A (2010): Diagnosis of premature rupture of membranes: inspiration from the past and insights for the future. J Obstet Gynaecol Can. 2010;32:561569. [PubMed]

16. El-zanty F \& Way A.(2011): Egyptian -term demographic health survey.

17. Erin A, Christopher P, Angeline A, Alma A, Job D, Ivo M\& Suparat P.( 2014): Factors Affecting Attendance at and Timing of Formal Antenatal Care. Pak J Med Sci. 9(5):800-805 e93025

18. Gupta R, Talukdar B (2017): Frequency and Timing of Antenatal Care Visits and Its Impact on Neonatal Mortality in the EAG States of India. J Neonatal Biol 6: 263. doi:10.4172/2167-0897.1000263

19. Ishtiaque S., Malik U., Jadoon A. (2016): Obstetric outcomes in booked and unbooked mothers. ISRA Medical Journal, 8 (3), July Sep 2016

20. Jaspinder $K$ and Kawaljit $K$ (2012): Obstetric complications: Primiparity Vs.Multiparity European Journal of Experimental Biology, 2012, 2(5):1462-1468 21. 21.

oshi C, Torvaldsen S, Hodgson R \& Hayden A. (2014): Factors associated with the use and quality of antenatal care in Nepal: a population-based study using the demographic and health survey data. BMC Pregnancy Childbirth. 14(1):300-306.

22. Kim LH, Caughey AB, Laguardia JC, Escobar GJ, J Perinatol, 2012, 32,260.

23. Larsen JV, van Middelkoop A (2004): WHO analysis of causes of maternal death: a systematic review. Lancet 2004; 367(9516): 1066- 74.

24. Liu J, Feng Z-C, Wu J (2010): The incidence rate of premature rupture of membranes and its influence on fetal-neonatal health: a report from mainland China. J Trop Pediatr. 2010;56:36-42. [PubMed]

25. Majoko F, Nyström L, Munjanja S, Mason E and Lindmark $G$ (2004): Relation of Parity to Pregnancy Outcome in a Rural Community in Zimbabwe African Journal of Reproductive 26. 26. Health 2004; 8[3] 198-206.

ugo N S, Dibley M J \& Agho K E. (2015): Prevalence and risk factors for non-use of antenatal care visits: analysis of the 2010 South Sudan household survey. BMC Pregnancy Childbirth. 15(1).
27.

umbare S \& Rege R. (2011): Antenatal care services utilization, delivery practices and factors affecting them in the tribal area of North Maharashtra. Indian J Community Med. 36(4): 287.

28. Muti M, Tshimanga M, Notion GT, Bangure D, and Chonzi P(2015): Prevalence of pregnancy-induced hypertension and pregnancy outcomes among women seeking maternity services in Harare, Zimbabwe. BMC Cardiovascular Disorders (2015) 15:111 https://www.biomedcentral.com/submit 17-22018

29. Osungbade KO, Ayinde OO (2011): Birth outcomes among booked and unbooked women at a secondary health facility in Southwest Nigeria: Implications for strengthening perinatal health services. J Child Health Care 2011;15:320-8.

30. Patki VK., \& Antin J V (2017): Maternal antenatal profile and immediate neonatal outcome in very low birth weight babies International Journal of Medical Pediatrics and Oncology, April-June, 2017:3(2):64-70

31. Polite O, Ijeoma OC, Abimbola KO, Joel AA (2017): The effect of frequency of antenatal visits on pregnancy outcome in Kaduna, Northern Nigeria. (C) 2017 Tropical Journal of Obstetrics and Gynaecology | Published by Wolters Kluwer - .Medknow http://www.tjogonline.com on Thursday, March 15, 2018, IP: 193.227.61.252]

32. Raatikainen $\mathbf{K}$, Heiskanen $\mathbf{N}$, Heinonen $\mathbf{S}$ (2010): Under-attending free antenatal care is associated with adverse pregnancy outcomes. BMC Public Health. 2010 Sep 27;7:268. https://doi.org/10.1186/1471-2458-7-268 PubMed PMID: 17900359; PubMed Central PMCID: PMC2048953.

33. Racine A. D. (2011): Pregnancy Care Program to Improve Maternal and Infant Health Outcomes. Report to: Joint Fiscal Committee Agency of Human Services. September 26, 2011

34. Roy R, \& Vernekar M (2017): Feto-maternal outcome in grand multipara. International Journal of Reproduction, Contraception, Obstetrics and Gynecology Roy R et al. Int J Reprod Contracept Obstet Gynecol. 2017 Jul;6(7):2846-2851 www.ijrcog.org

35. Singh A K, Devi U, Gandhi N, Vimal $M$ (2018): Study of Proportion of Anemia and Variation of Hematological Parameters in Pregnancy JMSCR Vol 06 Issue 02 Page 202215 February 2018

36. Taner CE, Ekin A, Solmaz U, Gezer C, Çetin B, Kelesoglu M, et al (2015): Prevalence and risk factors of anemia among 
pregnant women attending a high-volume tertiary care center for delivery. J Turk Ger Gynecol Assoc 2015; 16:231-6.

37. Titaley C R, Hunter CL, Heywood P \& DibleyM J. (2010): Why don't some women attend antenatal and postnatal care services?: a qualitative study of community members' perspectives in Garut, Sukabumi and Ciamis districts of West Java Province, Indonesia. BMC Pregnancy Childbirth. 10(1): 10-61.

38. Tucker A, Ogutu D, Yoong W, Nauta M and Fakokunde A(2010): The unbooked mother: a cohort study of maternal and fetal outcomes in a NorthLondonHosptial. Arch Gynecol Obstet. 2010 ; 281 (4): 613-16

39. Tuladhar H \& Dhakal N (2011): Impact of Antenatal Care on Maternal and Perinatal Outcome: A Study at Nepal Medical College Teaching Hospital. NJOG 2011 Nov-Dec; 6 (2): $37-43$
40. UNICEF. (2015). The State of the world's children: Maternal and Newborns health.

41. Vogel JP, Lee AC, Souza JP (2014): Maternal morbidity and preterm birth in 22 low- and middle-income countries: a secondary analysis of the WHO Global Survey dataset. BMC Pregnancy Childbirth. 2014;14:56.[PMC free article] [PubMed]

42. World Health Organization (2018): WHO Recommendations on Antenatal Care for a Positive Pregnancy Experience: Summary Highlights and Key Messages from the World Health Organization's $2016 \quad$ Global Recommendations for Routine Antenatal Care January 2018 www.mcsprogram.org

43. Yakoob MY, Menezes EV, Soomro T, Haws RA, Darmstadt GL, Bhutta ZA (2009): Reducing stillbirths: behavioral and nutritional interventions before and during pregnancy. BMC Pregnancy \& Childbirth 2009, 9(1):S3.

44. Ziyo F Y, Matly F A, Mehemd G M, Dofany E M (2009): Relation between Prenatal care and Pregnancy Outcome at Benghazi. Sudanese Journal of Public Health October 2009, Vol4 No4 Correspondence baby.frindly@yahoo.com. 